\title{
YKL-40 protein expression in normal adult human tissues - an immunohistochemical study
}

Merete Ringsholt • Estrid V. S. Høgdall •

Julia S. Johansen · Paul A. Price $\cdot$ Lise H. Christensen

Published online: 10 July 2007

(C) Springer Science+Business Media B.V. 2007

\section{Erratum to: J Mol Hist}

DOI 10.1007/s10735-006-9075-0

Due to an unfortunate mistake, Figs. 1-6 were printed in black and white.

The online version of the original article can be found under doi: 10.1007/s10735-006-9075-0.

M. Ringsholt · E. V. S. Høgdall · L. H. Christensen Department of Pathology, Bispebjerg Hospital, University of Copenhagen, Copenhagen, Denmark

M. Ringsholt ( $\square)$

Faculty of Medical Laboratory Science, University College Oeresund, Faelledvej 12, 2200 Copenhagen N, Denmark

e-mail: mri@bioanalytiker.dk

E. V. S. Høgdall

Department of Virus, Hormones and Cancer, Danish Cancer

Society, Copenhagen, Denmark

J. S. Johansen

Department of Rheumatology, Herlev Hospital, University

of Copenhagen, Copenhagen, Denmark

P. A. Price

Department of Biology, University of California, San Diego,

La Jolla, San Diego, CA, USA 
Fig. 1 (A-D) Parathyroid tissue stained for YKL-40 with the primary specific antibody (mAb 201F9) (A) and for a positive control antibody (mAb 115F6D10) (B). Both antibodies give an intense cytoplasmic staining of the endocrine chief cells. An island of fibrous tissue in the centre containing just a few stained chief cells remains unstained $(\times 40) \mathbf{C}, \mathbf{D}$. Appendix mucosa incubated with $(\mathbf{C})$ and without (D) preabsorption of the mAb 201F9 antibody. No staining is seen when the $\mathrm{mAB}$ 201F9 was preabsorbed with the YKL-40 protein $(\mathbf{C})(\times 40)$
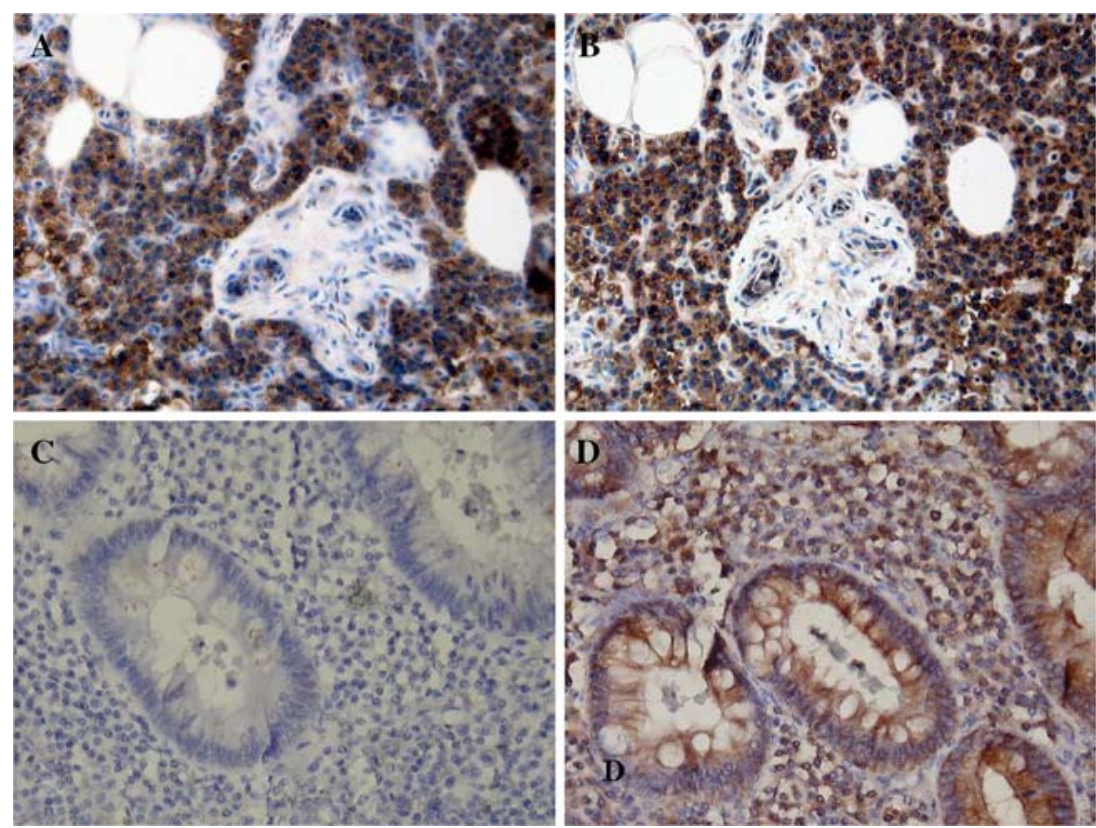
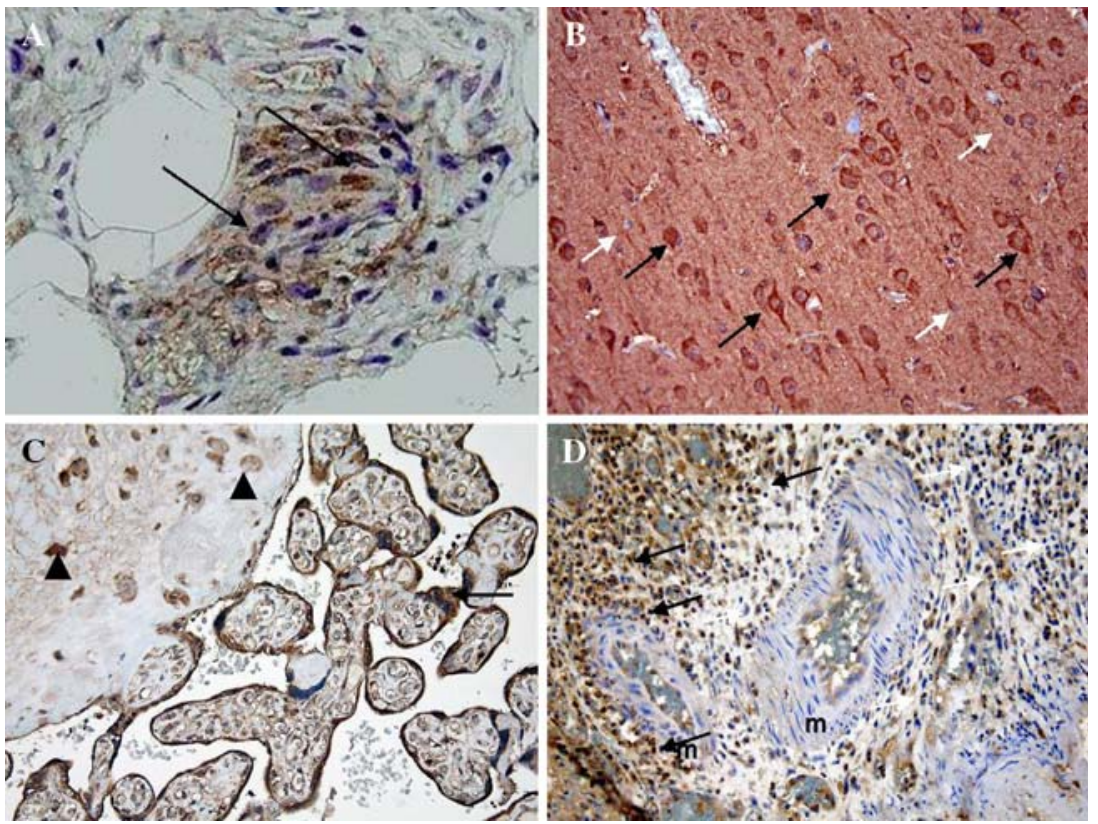

Fig. 2 (A) Fibers of a peripheral nerve. The cells (arrows) are intensely stained $(\times 40)$. (B) Brain tissue, gray matter. The neurons are intensely stained (black arrows). The microglia are less intensely stained or not stained at all (white arrows). The dark colour of the background is due to the entanglement of YKL-40 positive neurofibrils and dendrites, which are normally demonstrated by silver stain $(\times 40)$. (C) Placental tissue. Both trophoblast (arrow) and the

endothelium of capillaries (arrowheads) are intensely stained $(\times 40)$. (D) An area from the appendix wall containing both stained (black arrows) and unstained (white arrows) polymorph nuclear granulocytes. Some stained debris is seen in the background to the left. Two vessels with positive endothelium and negative muscle walls (m) are seen in the centre $(\times 40)$ 
Fig. 3 (A) Parasympathetic ganglion of the myenteric plexus of the colon. Individual cells are intensely stained (arrow) $(\times 40)$. (B) Pancreas section with intensely stained islet cells (arrow) and more weakly stained acinar and ductal cells $(\times 40)$. (C) Thyroid tissue. The follicular epithelial cells are weakly to moderately stained (arrows) ( $\times 40)$. (D) Liver tissue with a portal tract centrally. The hepatocytes are moderately stained (white arrow), whereas the bile duct epithelial cells are intensely stained (black arrow) $(\times 20)$

Fig. 4 (A) Parotic gland. The ducts are intensely stained (arrows) in contrast to the weakly stained serous alveolar cells $(\times 40)$. (B) Breast lobule. The secretory tubules are moderately to intensely stained (arrows). The ducts are negative or weakly positive (arrowhead) $(\times 40)$. (C) Corpus endometrium of the uterus in proliferation phase. The proliferating glands are moderately to intensely stained (arrows) $(\times 40)$. (D) Kidney parenchyme. Some of the tubules are moderately to intensely stained (arrows). The glomerulus is negative (arrowhead). Endothelial cells of a muscular artery (top left) are positive, whereas the muscle cells of the wall $(\mathrm{m})$ are negative $(\times 40)$
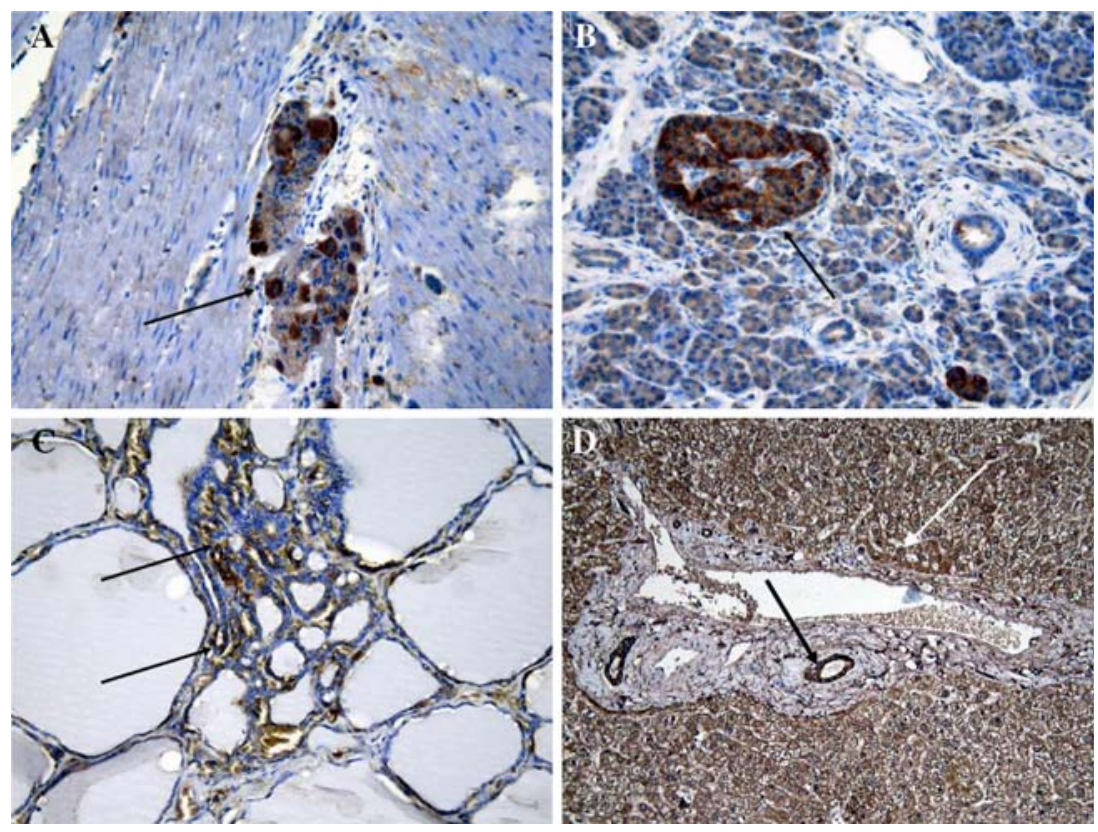
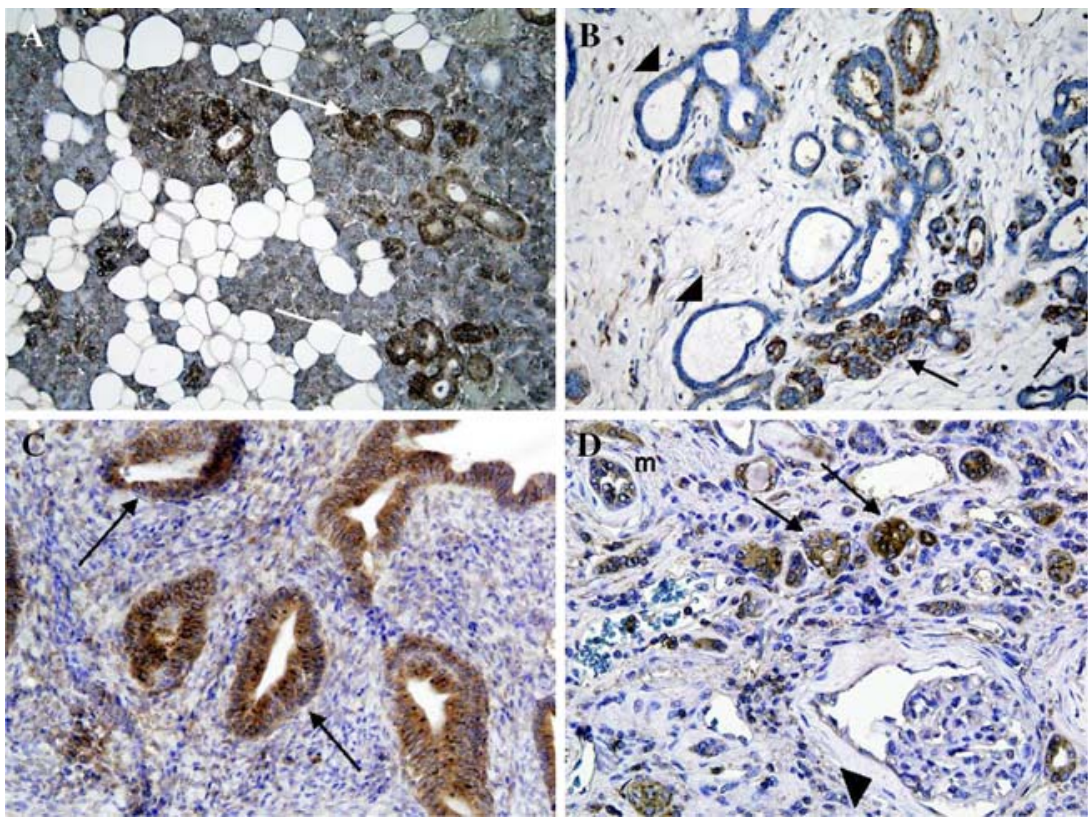

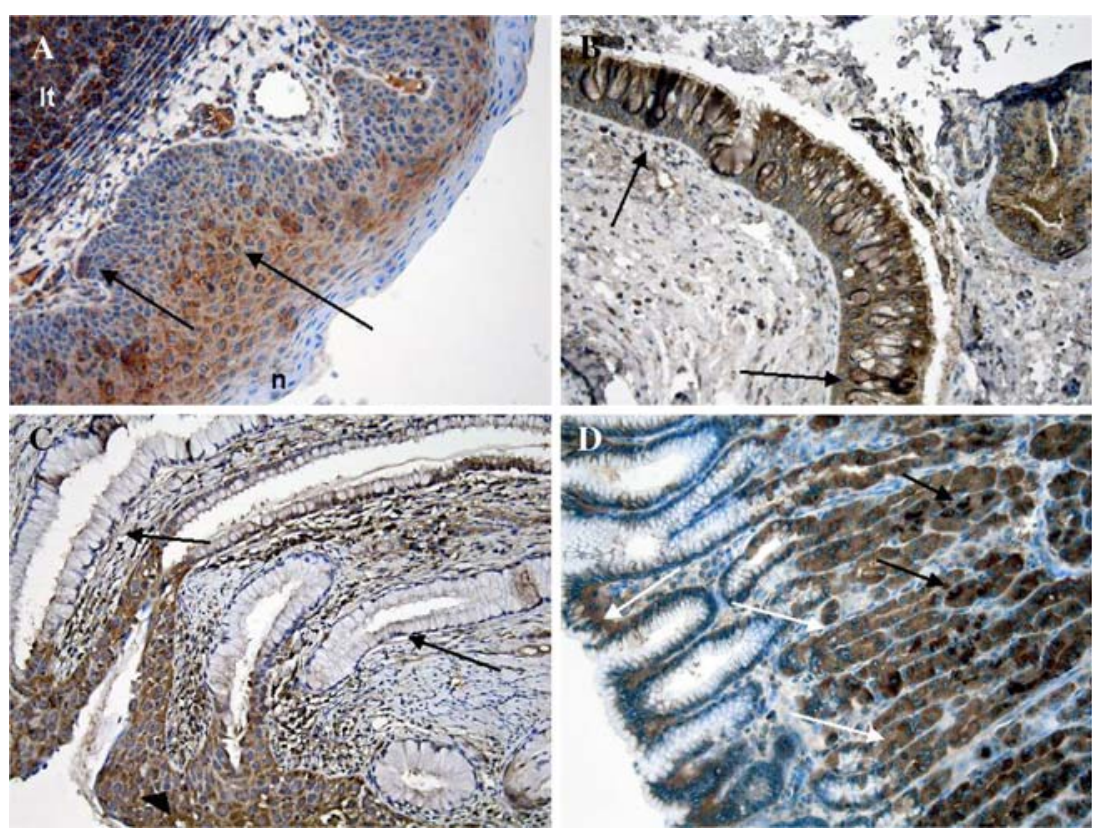

Fig. 5 (A) Squamous epithelium of palatine tonsil and underlying lymphatic tissue (1t). The intermediate and lower parts of the epithelium are stained (arrows). The superficial layers are negative (n) $(\times 40)$. (B) Respiratory epithelium of bronchus. Some cells are intensely stained (arrow), others are weakly to moderately positive $(\times 40)$. (C) Transformation zone of the cervical canal/portio. The

mucous glands of the cervix are negative (arrows). The emerging squamous epithelium is moderately positive (arrowhead) $(\times 40)$. (D) Gastric mucosa. The parietal cells are intensely stained (black arrows). The chief cells and the surface mucous epithelial cells are more weakly stained (white arrows) $(\times 40)$

Fig. 6 (A) Synovial lining cells showing a weak to moderate staining (black arrows). Scattered plasma cells are stained as well (white arrows) $(\times 40)$. (B) Cartilage abutting compact bone tissue (upper left). The chondrocytes are weakly to moderately stained (arrows) ( $\times 40)$. (C) Trabecula of bone tissue separated by fibrous tissue. Both osteoblasts and osteocytes (arrows) are moderately stained $(\times 40)$. (D) Bone marrow section. Most hematogenous precursors, including megacaryocytes, are positive (arrows). Only some lymphocytes (l) and all the erythrocytes (e) are negative $(\times 40)$
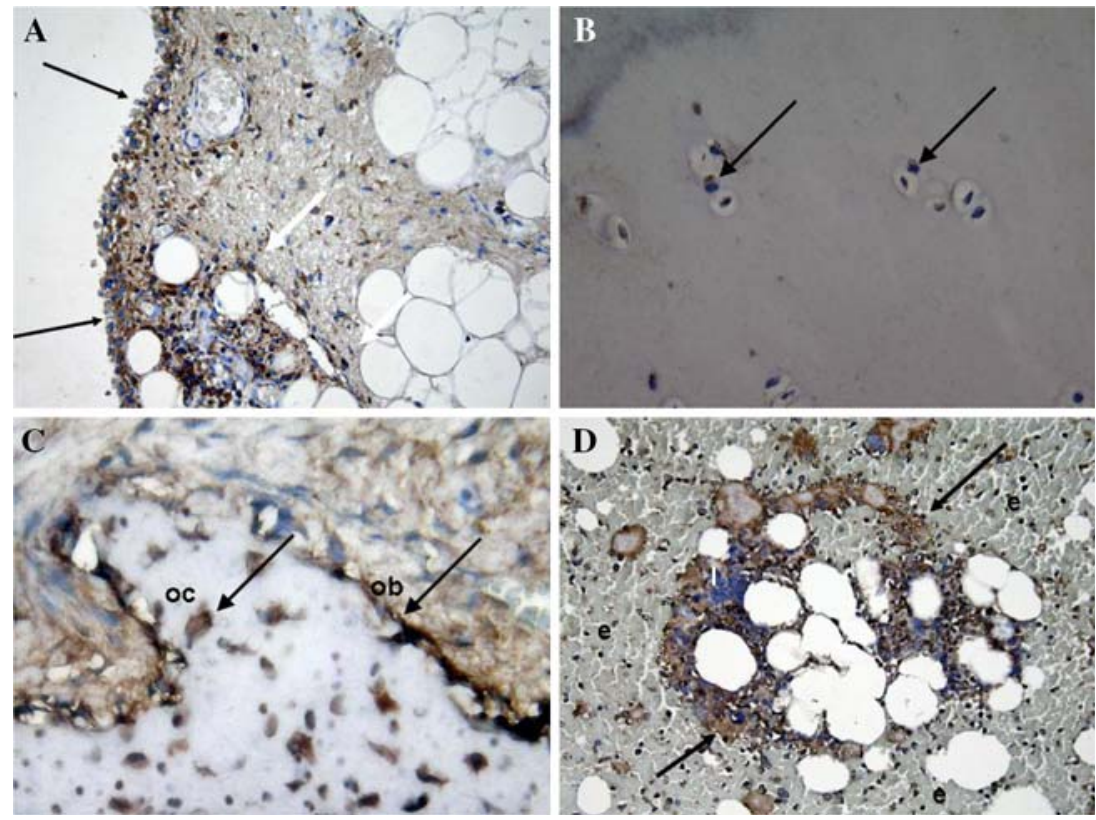